\title{
Defecografía por resonancia magnética y su utilidad en el estudio de disfunción del piso pélvico
}

\author{
Antonio Vallejos $C^{1}$, Gabriela Rodríguez $T^{1}$, Sofía Palacios $\mathbf{M}^{1}$, Giancarlo Schiappacasse $F^{2}$.
}

1. Médico Residente de Radiología, Universidad de Santiago de Chile, Santiago, Chile.

2. Médico Radiólogo. Profesor Adjunto Hospital Militar-Universidad de Santiago de Chile. Facultad de Medicina. Clínica Alemana de Santiago - Universidad del Desarrollo. Santiago, Chile.

\section{Magnetic resonance defecography and its role in pelvic floor dysfunction}

\section{Resumen:}

La disfunción del piso pélvico representa un amplio espectro de trastornos funcionales complejos, los que pueden afectar a uno o más, de los tres compartimentos que componen la pelvis. Estos desórdenes son más frecuentes en mujeres posmenopáusicas, por lo que su prevalencia va en aumento, en concordancia con el envejecimiento de la población. Este conjunto de trastornos, suelen determinar un importante deterioro en la calidad de vida, principalmente debido a las manifestaciones clínicas que pueden presentar, tales como dolor pélvico, incontinencia urinaria y/o fecal, constipación o prolapso de órganos pélvicos. El diagnóstico de estas patologías se logra de forma más apropiada mediante la evaluación por imágenes; cuando el diagnóstico realiza sólo en base a la historia clínica y el examen físico, hay una tasa de error significativa y, en consecuencia, pueden ocurrir intervenciones fallidas o innecesarias. Por lo anterior, la defecografía por resonancia magnética (D-RM) juega un rol fundamental, especialmente previo a intervenciones quirúrgicas, ya que es una modalidad no invasiva que aporta información multiplanar y dinámica, con alta resolución temporo-espacial y que permite valorar de manera precisa la anatomía y alteraciones de los compartimentos que conforman el piso pélvico, sin riesgo de irradiación para el paciente. Los objetivos de este artículo son describir el protocolo técnico a utilizar en la D-RM ilustrar a través de imágenes representativas la anatomía normal de la pelvis femenina junto con sus puntos, líneas, ángulos y medidas más importantes; y ejemplificar los hallazgos imagenológicos de los desórdenes más frecuentes que afectan al piso pélvico.

Palabras clave: Constipación; Defecografía por Resonancia Magnética; Disfunción piso pélvico.

\begin{abstract}
:
The pelvic floor dysfunction represents a broad spectrum of complex functional disorders that can affect one or more of the three compartments that constitute the pelvic floor. These disorders are more common in postmenopausal women, so their prevalence is increasing accordingly to the aging of the population. This group of disorders usually result in a significant quality of life deterioration, mainly due to the clinical manifestations that they may present, such as pelvic pain, urinary and/or fecal incontinence, constipation or pelvic organ prolapse. The diagnosis of this group of diseases is most adequately achieved with image evaluation. When the diagnosis is based only on the clinical history and physical examination, there is a significant error rate and, consequently, more failed interventions. Therefore, Magnetic Resonance (MR) defecography plays a fundamental role, especially prior to surgical interventions, since it is a non-invasive modality that provides multiplanar and dynamic information, with high temporal and spatial resolution, allowing the precise assessment of the anatomy and alterations of the compartments that make up the pelvic floor, without any radiation for the patient. The aim of this article is to describe the technical protocol to be used in MR defecography. To illustrate through representative images the normal anatomy of the female pelvis including its hallmarks, lines, angles and measurements. And also, to illustrate the imaging findings of the most frequent disorders affecting the pelvic floor.
\end{abstract}

Keywords: Constipation; MRI defecography; Pelvic floor dysfunction. 
Vallejos $A$, et al. Defecografía por resonancia magnética y su utilidad en el estudio de disfunción del piso pélvico. Rev Chil Radiol 2021; 27(2): 76-87.

*Correo electrónico: Giancarlo Schiappacasse Faúndes / gschiappacasse@gmail.com

Trabajo enviado el 08 de agosto de 2020. Aceptado para publicación el 29 de enero de 2021.

\section{Introducción}

La disfunción del piso pélvico representa un problema clínico habitual, con impacto significativo en la calidad de vida'.

Los factores de riesgo asociados a la disfunción del piso pélvico son múltiples, entre los que podemos nombrar la edad avanzada, embarazo, obesidad, menopausia y otras ${ }^{2}$. Esta patología puede presentar diversas manifestaciones clínicas como incontinencia, constipación, prolapso y una combinación de ellas ${ }^{3}$.

La disfunción anorrectal por sí sola representa un $10-20 \%$ de las consultas gastroenterológicas ${ }^{4}, y$ se proyecta que en los próximos 30 años se incremente en un $45 \%$ la demanda de especialistas para la evaluación imagenológica y el manejo de estas patologías 4 .

La historia clínica y examen físico corresponden al primer paso en la evaluación de la disfunción del piso pélvico, sin embargo, es fundamental una aproximación multidisciplinaria, incluyendo una detallada evaluación de las imágenes, para un diagnóstico precoz y adecuada planificación quirúrgica'.

Este conjunto de patologías presenta una alta tasa de recurrencia, hasta un $10-30 \%$ de las correcciones quirúrgicas de uno de los compartimientos afectados pueden presentar reaparición de los síntomas, posiblemente debido a la afección concomitante de otro compartimiento, que puede no haber sido manejado o evaluado de forma adecuada ${ }^{2}$.

Las imágenes, por lo tanto, cobran un rol fundamental para una correcta y completa evaluación de esta compleja patología. Durante la última década, la D-RM con secuencias dinámicas ha demostrado ser precisa y confiable para identificar alteraciones y disfunción del piso pélvico, especialmente cuando hay múltiples compartimentos involucrados, dado que permite una visualización simultánea de éstos ${ }^{2}$.

\section{Desarrollo}

Históricamente la evaluación imagenológica del piso pélvico se ha realizado mediante las técnicas radiológicas convencionales: cisto-uretrografía miccional, defecografía convencional y recientemente a través de ecografía dinámica del piso pélvico. Estas técnicas siguen siendo métodos prácticos y rentables en la evaluación de la disfunción anorrectal y pélvica no complicada. Sin embargo, durante las últimas décadas, la RM con secuencias dinámicas ha de- mostrado ser precisa y confiable para identificar la debilidad del piso pélvico, dado que permite simular condiciones asociadas a estas patologías ${ }^{3}$.

Descrita el año 1952, la defecografía convencional era considerada el estándar de referencia para la evaluación de desórdenes de piso pélvico. Este examen consiste en la inyección de contraste en la vagina, vejiga y recto, y posterior obtención de imágenes mediante fluoroscopía. Tiene la ventaja de realizarse en posición fisiológica para el paciente (sedestación) y desde el punto de vista funcional aporta información certera ${ }^{5}$.

Sin embargo, presenta varias desventajas como la incapacidad de evaluar todos los compartimentos simultáneamente, la falta de evaluación de los tejidos pelvianos y la incomodidad del paciente al realizar maniobras defecatorias con el radiólogo presente en la sala. Por estos motivos, y dado que es un examen que utiliza radiación ionizante y requiere destreza del operador, su uso ha disminuido de manera significativa en los últimos años.

La D-RM es un estudio dinámico que permite evaluar los órganos pélvicos se realiza en tiempo real, mientras el paciente se encuentra en reposo (decúbito supino) y al realizar maniobras dinámicas de pujo/valsalva y evacuación con el recto previamente preparado y distendido con gel de ultrasonido.

Dentro sus principales ventajas está la no utilización de radiación ionizante, su capacidad para visualizar tejidos extraluminales con gran resolución temporal y no es necesario utilizar medios de contraste oral ni endovenoso ${ }^{5}$.

La principal desventaja es la posición horizontal (no fisiológica) del paciente durante el estudio. Sin embargo, se ha demostrado que no hay diferencia significativa en la obtención de los parámetros a evaluar, independiente de la posición del paciente ${ }^{1,6}$. La sensibilidad y especificidad de la D-RM son comparables a la defecografía convencional por lo que representa una excelente alternativa a este método ${ }^{5,7}$.

\section{Técnica}

Preparación previa del paciente: La literatura describe que la preparación del colon previo al estudio no es estrictamente necesaria ${ }^{8,9}$, sin embargo, la mayoría de los centros presentan sus protocolos propios.

Técnica de imagen: Respecto al protocolo de 
realización de examen, este se puede dividir en evaluación estática y dinámica.

Evaluación estática: Se realizan adquisiciones ponderadas en T2 spin-echo en los 3 ejes (axial, coronal y sagital) a nivel de la pelvis, para evaluar la anatomía y alteraciones estructurales.

Evaluación dinámica: Se introduce gel de ultrasonido vía rectal y/o vaginal, dependiendo del segmento a evaluar, a través de una sonda. En promedio se utilizan 150-300 cc según cada paciente y su tolerancia.

El paciente se debe posicionar en decúbito supino en la mesa del resonador (con o sin rodillas dobladas) con una almohadilla debajo para optimizar la posición. Se recomienda que la vejiga esté parcialmente distendida, y que el paciente no tenga deseos de orinar, para mayor comodidad.

Se realizan secuencias sagitales steady-state (SSFP) que permiten obtener imágenes dinámicas en modo cine, en línea media, las cuales presentan un nombre variable de acuerdo a la marca del equipo (TrueFISP, FIESTA, B-FFE); las adquisiciones se efectúan con un grosor de corte de $5 \mathrm{~mm}$ y en secuencias de 60-90 imágenes de 1 segundo cada una.

En el estudio dinámico, se realizan las siguientes secuencias: 1) Fase de reposo: proporciona información sobre el estado basal de los órganos pelvianos. 2) Fase de contracción: proporciona información sobre la fuerza e integridad de los músculos del piso pélvico; 3 ) Fase de valsalva (incluyendo pujo) o de esfuerzo: Evalúa la competencia de los esfínteres interno y externo; 4) Fase de evacuación (defecatoria): se considera la fase más importante del examen, permite evaluar de forma más precisa las alteraciones del piso pélvico (Figura 1).

\section{Reparos anatómicos del piso pélvico Anatomía pélvica}

El piso pélvico comprende 3 compartimentos: Anterior, que contiene la vejiga y la uretra; Central, que contiene el útero y la vagina; Posterior, que contiene el canal anal, el recto y el colon sigmoides (Tabla 1). Las estructuras de soporte consisten en una interacción compleja entre huesos, músculos, ligamentos y órganos. Los ligamentos, músculos y fascia constituyen el sistema que da forma y función a los órganos, dado que éstos no tienen forma ni fuerza inherentes.

Las principales estructuras de soporte se describen a continuación, junto con los reparos anatómicos más importantes, representados de forma esquemática en la figura 2.

- Diafragma pélvico: Compuesto por los músculos isquiococcígeo y elevador del ano. El músculo elevador del ano está formado por los músculos iliococcígeo, puborrectal y pubococcígeo. El músculo puborrectal se origina en el borde inferior del pubis y se extiende en forma de "sling" o "honda" alrededor de la porción posterior de

Tabla 1. Descripción de los compartimentos del piso pélvico.

\begin{tabular}{|ll|}
\hline Compartimento & Órganos \\
\hline Anterior $(\mathrm{CA})$ & Vejiga y Uretra \\
Medio (CM) & Vagina y Útero \\
Posterior (CP) & Recto y Ano \\
\hline
\end{tabular}
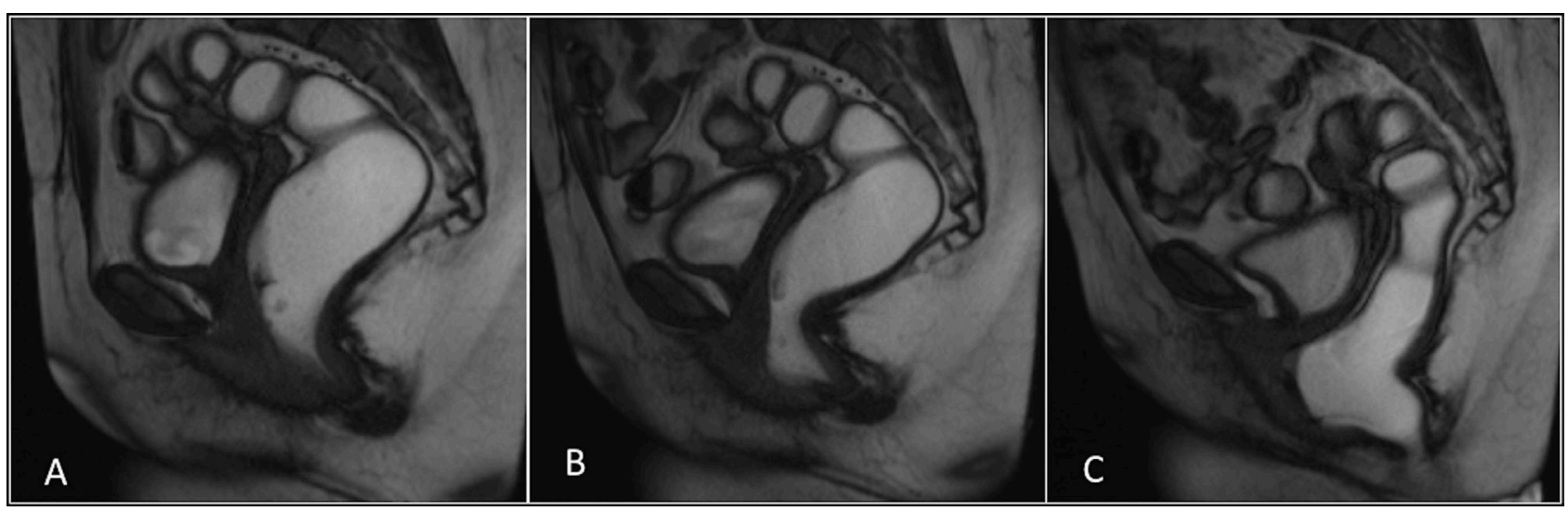

Figura 1 A, B y C: RM de pelvis con adquisiciones ponderadas en T2 spin-echo sagitales, durante la fase de (A) reposo, (B) entrenamiento y $(C)$ defecación, para la evaluación dinámica de reparos y competencia de estructuras anatómicas con el fin de evaluar y calificar de forma más precisa la patología del piso pélvico. 


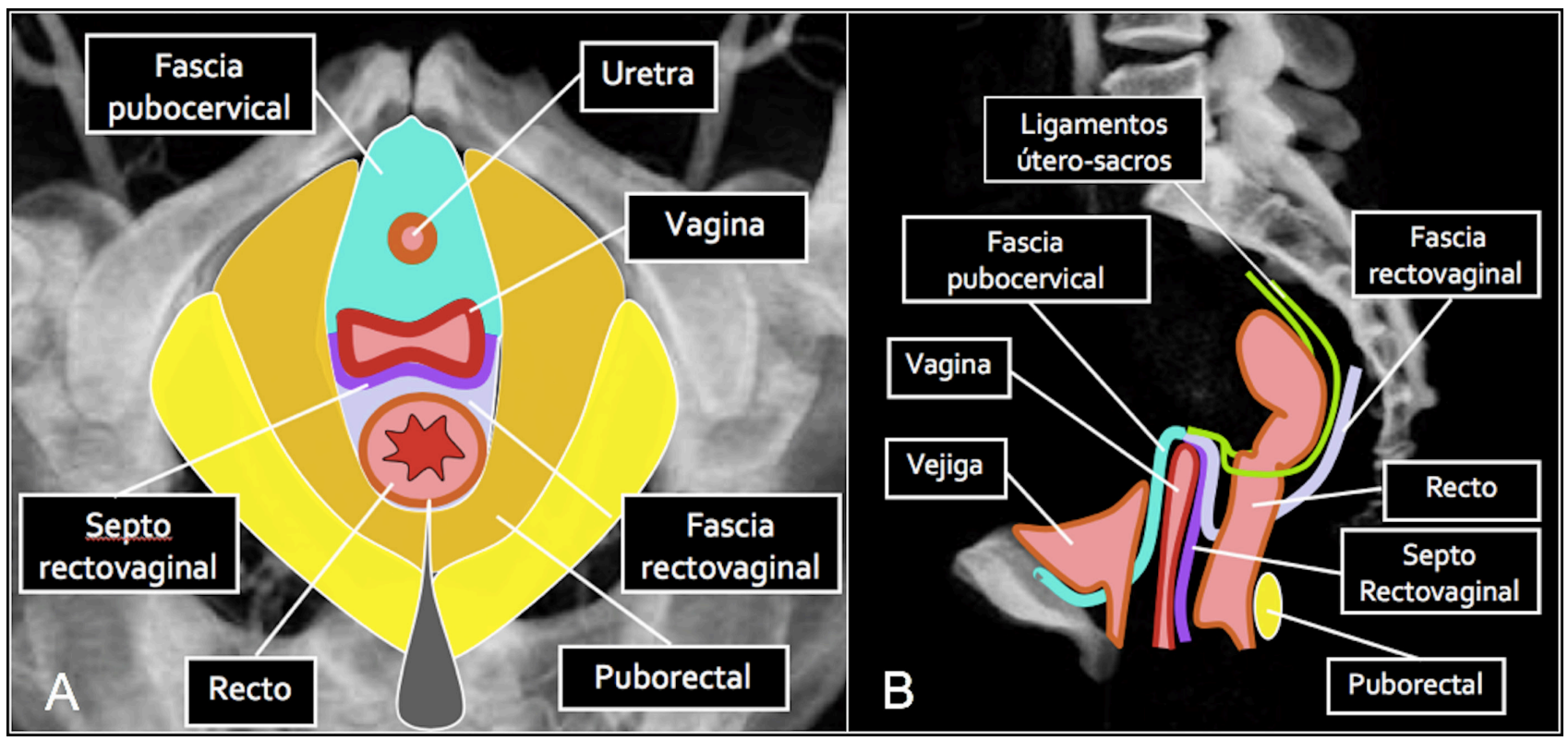

Figura 2 A y B: Representación anatómica esquemática de las estructuras de soporte del piso pélvico.

la unión anorrectal. El músculo ilio-coccígeo se origina en la espina isquiática y se extiende en forma de abanico con trayecto horizontal hacia el arco tendinoso del elevador del ano, formando parte del soporte lateral de los tres compartimentos.

- Fascia endopélvica: Corresponde a la capa más superior del piso pélvico, cubre el músculo elevador del ano y los órganos pélvicos en una lámina continua. En el compartimento anterior, se encuentra la fascia pubo-cervical que se extiende desde la pared vaginal anterior hasta el pubis. Posteriormente, a nivel del fondo del útero, se continúa con la fascia recto-vaginal, separada de ella por el septo recto-vaginal. Su rotura puede conducir a rectocele, enterocele o peritoneocele.

- Hiato del elevador o hiato pélvico (HP): El paso del recto a través del "sling" del músculo puborrectal forma un hiato, llamado hiato del elevador, punto donde finalmente se encuentran incluidos los tres compartimientos del piso pelviano.

- Ligamentos: En el compartimento anterior hay tres grupos de ligamentos que sostienen la uretra femenina: los peri-uretrales (ventrales a la uretra), los para-uretrales (laterales a la uretra) y los pubo-uretrales (desde el hueso pélvico hasta la pared ventral de la uretra). En el compartimento medio, existen condensaciones de tejido elástico de la fascia endopélvica, conocidos como paracolpio y parametrio, los que rodean la vagina y el útero lateralmente. En el segmento caudal de los ligamentos anchos, existen condensaciones que se denominan ligamentos cardinales y que se continúan con el paracolpio y parametrio, así como con la fascia pubocervical. Los ligamentos útero-sacros unen el cuello uterino y los fornices vaginales posteriores al sacro. En el compartimento posterior, la condensación de la fascia endopélvica se llama tabique recto-vaginal y se extiende entre la pared posterior de la vagina hasta la pared anterior del recto. Los ligamentos rectales laterales son el soporte fascial para el recto y se extienden desde la pared lateral de la pelvis hacia el recto.

- Diafragma urogenital: Localizado caudal al diafragma pélvico y anterior al ano-recto, está compuesto por tejido conectivo y músculo transverso profundo del periné, el que se origina en la rama isquiática. Proporciona soporte a la uretra distal y vagina.

\section{Líneas del piso pélvico y ángulo anorrectal}

En la evaluación pélvica no sólo se debe tener en consideración la anatomía normal, si no que se deben evaluar ciertas líneas y ángulos de referencia, útiles al momento de interpretar los hallazgos y determinar si existen de patologías. Estos reparos anatómicos, sus límites y utilidad práctica, se explican a continuación y en la tabla 2 y se ilustran en la figura 3.

a) Línea Pubo-coccígea (LPC): Crucial punto de referencia para la evaluación de múltiples patologías, que representa la altura del piso pélvico. Transcurre desde el borde inferior de la sínfisis del pubis hasta la última unión coccígea.

b) Línea M: Su medida depende de cuánto descien- 
Tabla 2. Descripción de las líneas del piso pélvico, sus límites y la utilidad práctica para este estudio.

\begin{tabular}{|lll|}
\hline & Límites & Utilidad práctica \\
\hline Línea pubo-coccígea (LPC) & $\begin{array}{l}\text { Desde el borde inferior de la sínfisis del pubis } \\
\text { hasta la última unión coccígea. }\end{array}$ & $\begin{array}{l}\text { Representa el nivel o altura del } \\
\text { piso pelviano. }\end{array}$ \\
Línea H & $\begin{array}{l}\text { Desde el borde inferior de la sínfisis del pubis } \\
\text { hasta el borde posterior de la unión ano-rectal. }\end{array}$ & $\begin{array}{l}\text { Representa el diámetro antero- } \\
\text { posterior del hiato del elevador. }\end{array}$ \\
Línea M & $\begin{array}{l}\text { Perpendicular a la LPC, hasta el punto más } \\
\text { posterior de la línea H. }\end{array}$ & $\begin{array}{l}\text { Representa la vertical descendente } \\
\text { del hiato del elevador. Delimita } \\
\text { cuanto es el descenso de la es- } \\
\text { tructura en estudio. }\end{array}$ \\
\hline
\end{tabular}

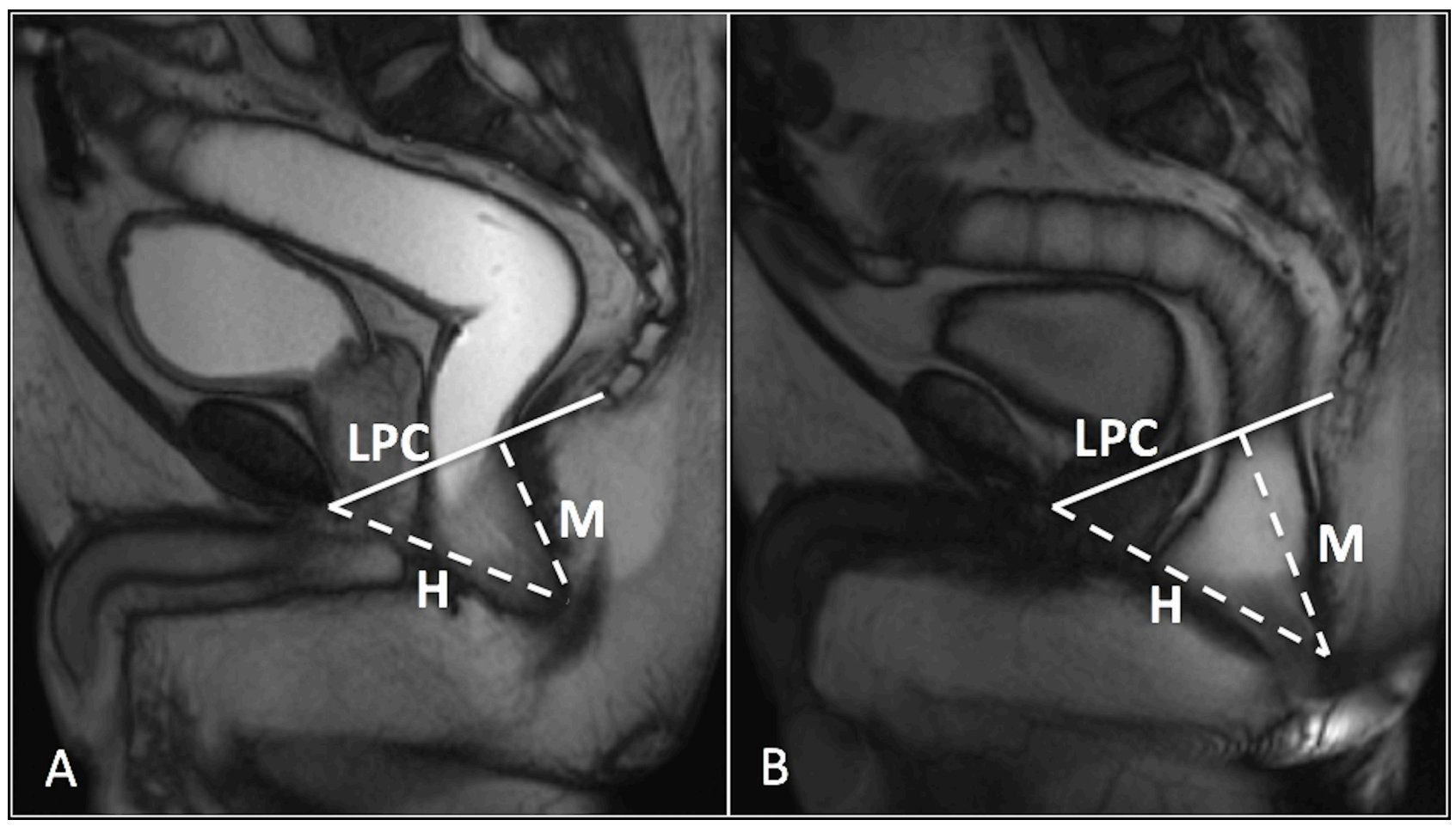

Figura 3 A y B: RM de pelvis con adquisiciones ponderadas en T2 spin-echo sagitales durante (A) fase en reposo y (B) fase defecatoria, en que se representan las líneas $P C L$, línea $H$ y línea $M$. La línea $M$ y $H$ se elongan fisiológicamente durante la defecación.

de el hiato pélvico por debajo de la LPC, traduciendo el descenso vertical de la estructura en estudio. La severidad de este descenso depende del órgano que se está evaluando y se cuantifica según lo descrito en la tabla 3.

c) Línea H: Representa el diámetro antero-posterior del hiato del elevador del ano. Refleja laxitud de los ligamentos de soporte y se encuentra aumentado si mide $>5 \mathrm{~cm}$.

d) Ángulo ano-rectal (AAR): Se mide entre el borde posterior de la parte distal del recto y el eje central del canal anal. Su amplitud está determinada por el funcionamiento del músculo puborrectal. Normalmente en reposo este ángulo mide $100-120^{\circ}$, durante la contracción disminuir a $85^{\circ}$ o ser $<20^{\circ}$ que en reposo y durante el pujo, relajarse hasta $135^{\circ} \mathrm{o}$ aumentar $>20^{\circ}$ respecto al reposo.

\section{Interpretación de imágenes}

La interpretación se puede dividir para efectos 
Tabla 3. Medidas para categorización del descenso vertical del hiato pélvico.

\begin{tabular}{|llc|}
\hline Severidad del descenso vertical del HP & Recto & Resto de estructuras \\
\hline Leve & $0-2 \mathrm{~cm}$ & $0-3 \mathrm{~cm}$ \\
Moderado & $2-4 \mathrm{~cm}$ & $3-6 \mathrm{~cm}$ \\
Acentuado & $>4 \mathrm{~cm}$ & $>6 \mathrm{~cm}$ \\
\hline
\end{tabular}

prácticos, en un estudio anatómico y uno funcional. Inicialmente se realiza una evaluación anatómica en adquisiciones T2, con el fin de descartar lesiones de las estructuras de soporte del piso pélvico. Posteriormente, se realizan las evaluaciones funcionales y dinámicas, de acuerdo a los hallazgos obtenidos durante las distintas fases ${ }^{3}$.

A continuación, se describen las alteraciones anatómicas y hallazgos en defecografía, de las patologías más habituales.

\section{Patología del compartimiento anterior}

Cistocele: se define como el descenso del borde inferior de la vejiga más de $1 \mathrm{~cm}$ por debajo de la LPC (Figura 4) y se manifiesta clínicamente como algún grado de incontinencia de esfuerzo ${ }^{10,11,12}$. Esta patología se produce por un desgarro en la fascia pubocervical, el cual puede localizarse en la porción central, lateral (paravaginal) o en ambas $^{13}$. Su gravedad se puede clasificar según el desplazamiento respecto a la LPC: Grado 1:<3 cm (Figura 4b); Grado 2: 3-6 cm; Grado 3: $>6 \mathrm{~cm}$.

Síndrome de hipermotilidad Uretral (SHU): El cistocele suele asociarse al SHU, esto ocurre dado que la uretra proximal y el cuello de la vejiga se movilizan en presencia de un cistocele. En esta situación, la pared posterior de la vejiga puede descender en una mayor magnitud que la pared anterior causando un descenso caudal y una rotación hacia anterior de la uretra, la que adopta una disposición característica, que se puede evidenciar en imágenes sagitales. Cuando el eje de la uretra rota sobre $30^{\circ}$ se diagnostica una hipermotilidad uretral $^{14}$ (Figura 5).

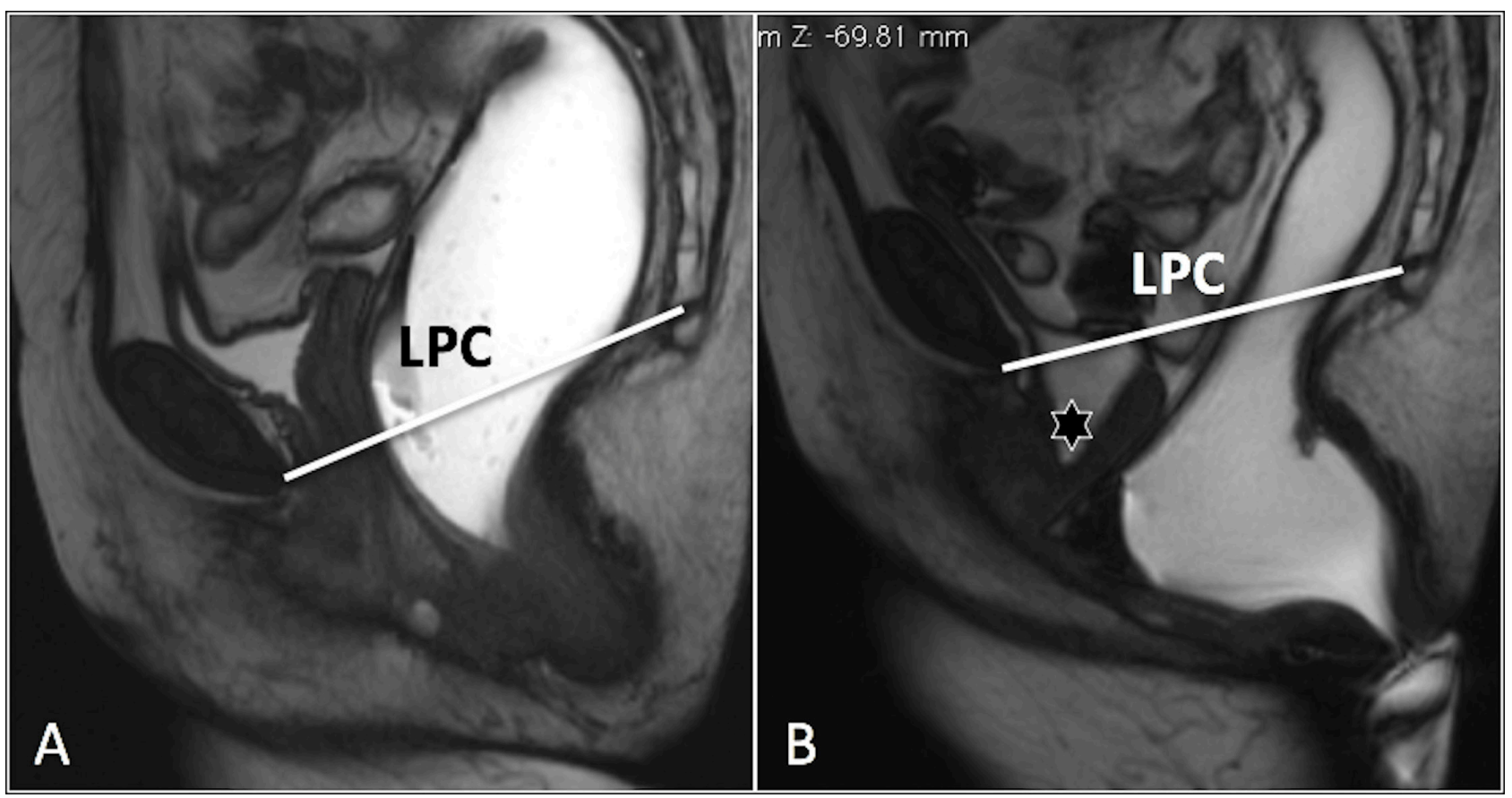

Figura 4 A y B: RM pelvis sagital en línea media, (A) en fase de reposo, se muestra la normal posición de la vejiga. La imagen en fase defecatoria (B), demuestra un descenso vesical (*) compatible con un cistocele grado 1. 


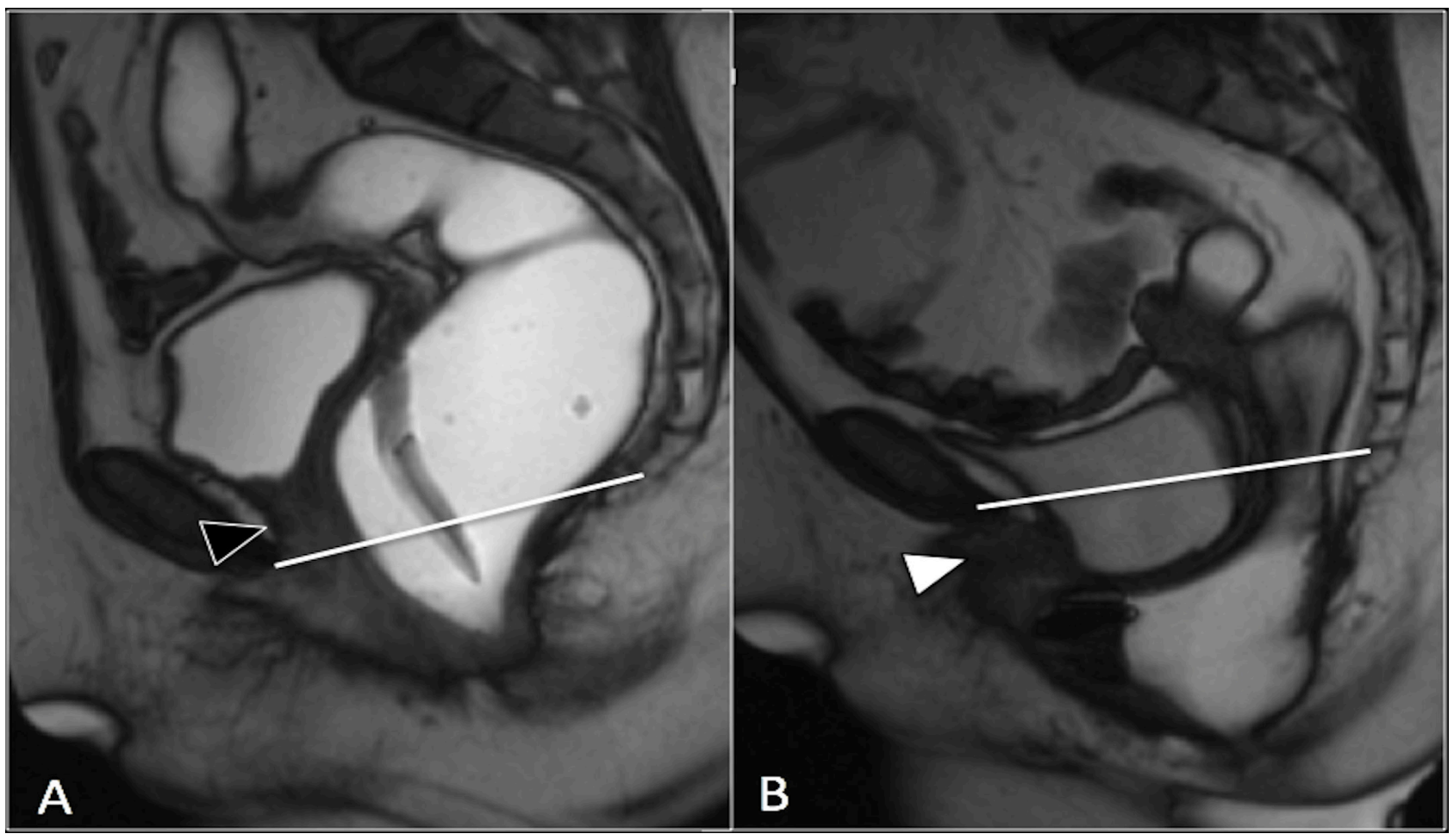

Figura 5 A y B: RM pelvis sagital en línea media, con imágenes en fase de reposo (A) y fase defecatoria (B), que grafican la posición normal de la uretra en fase de reposo (punta de flecha negra) y una rotación horizontal de la uretra (punta de flecha blanca) durante la fase defecatoria, en el contexto de un síndrome de hipermotilidad uretral, asociada en este caso a un cistocele moderado y un gran rectocele anterior.

\section{Patología del compartimiento medio}

Prolapso vaginal y uterino: La patología del compartimento medio incluye los prolapsos vaginales y uterinos. En su patogenia intervienen una laxitud aumentada y debilidad de los ligamentos úterosacros, de la fascia pubo-cervical y recto-vaginal; lo que permite una movilización anterior del cervix produciendo una retroversión progresiva uterina y posterior prolapso. El prolapso vaginal o cervical se define como el descenso de la cúpula vaginal bajo la LPC. El grado de prolapso de la cúpula vaginal o colpocele, se clasifica según el desplazamiento bajo la LPC: leve $<3 \mathrm{~cm}$; moderado entre $3-6 \mathrm{~cm}$; severo $\geq 6 \mathrm{~cm}^{8,10}$ (Figura 6).

En imágenes axiales, la vagina puede perder su morfología típica en "H" y se desplaza hacia inferior. En imágenes dinámicas, el segmento distal se desplaza hacia anterior. En imágenes coronales el músculo ilio-coccígeo puede aparecer aplanado o con convexidad inferior.

Al descender la vagina tiende a localizarse bajo del borde inferior de la vejiga, desplazando a su vez, la uretra hacia anterior ${ }^{15}$.

\section{Patología del compartimiento posterior}

Rectocele: Representa la patología más común del compartimento posterior, y se presenta cuando la pared rectal protruye sobrepasando el margen esperable ésta. En la mayoría de los casos el rectocele se produce por abombamiento de la pared anterior del recto desplazando la pared posterior de la vagina. Sin embargo, también puede ser posterior, lateral o circunferencial.

El rectocele se considera clínicamente relevante cuando ocurre retención del medio de contraste luego de las fases evacuatorias y se correlaciona clínicamente con sensación de evacuación incompleta ${ }^{8}$. Sus características principales son un tamaño $>2 \mathrm{~cm}$, retención del gel al final de la evacuación y reproducibilidad de los síntomas en controles posteriores. En los casos más severos es habitual la necesidad de asistencia para evacuar.

Respecto a la clasificación del rectocele anterior, se dividen según el desplazamiento bajo la LPC en: leve $<2 \mathrm{~cm}$; moderado $2-4 \mathrm{~cm}$; severo $>4 \mathrm{~cm}$ (Figura 7). Es frecuente el hallazgo de rectoceles pequeños en mujeres asintomáticas. Los rectoceles se pueden clasificar en completos o incompletos de acuerdo a la presencia o ausencia de gel remanente al final de la evacuación ${ }^{15}$. 


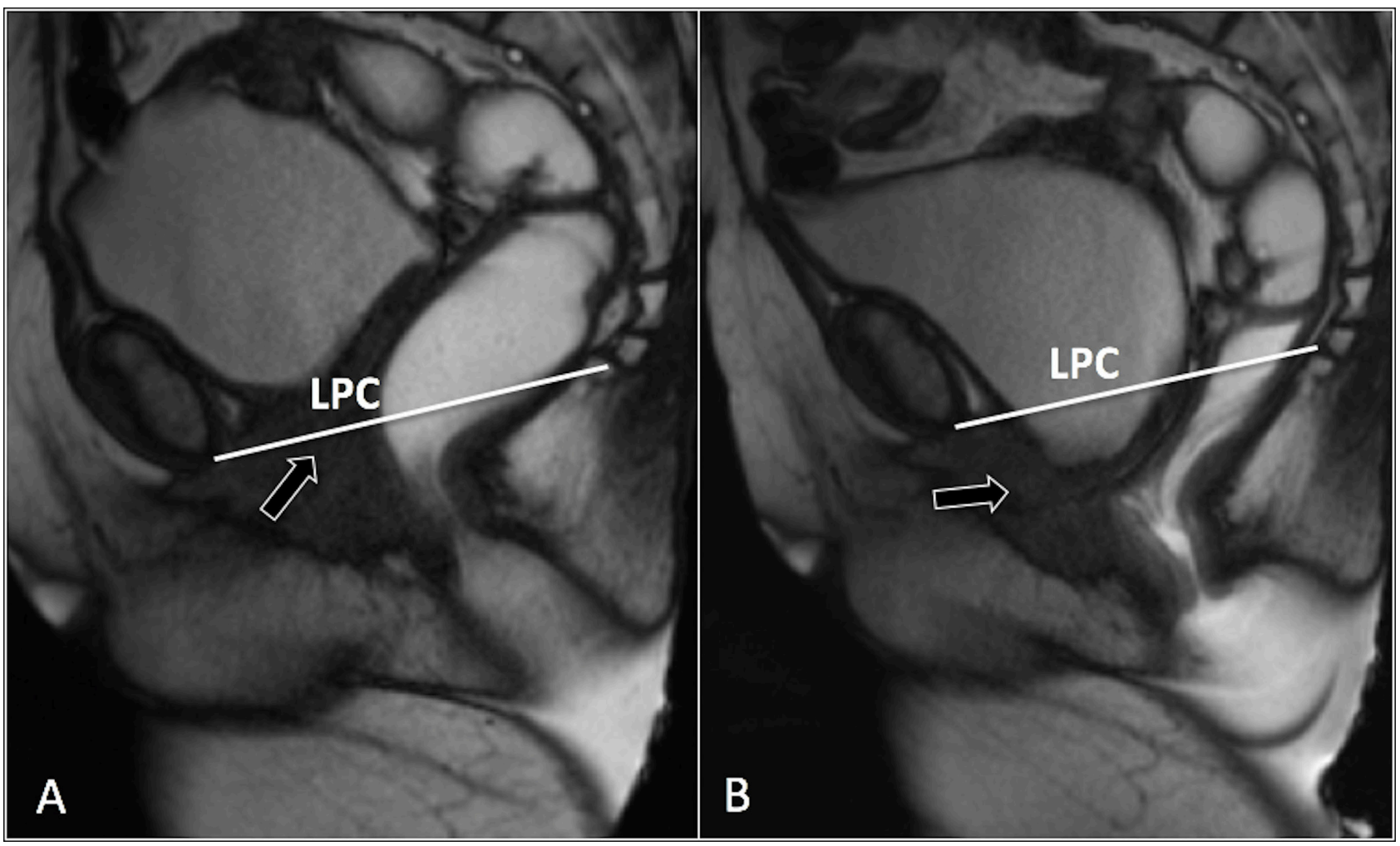

Figura 6 A y B: RM pelvis sagital en línea media, con imágenes en fase de reposo $(A)$ y fase defecatoria (B), que demuestran el descenso de la cúpula vaginal (flecha negra) $>2 \mathrm{~cm}$ desde la $L P C$, compatible con colpocele.

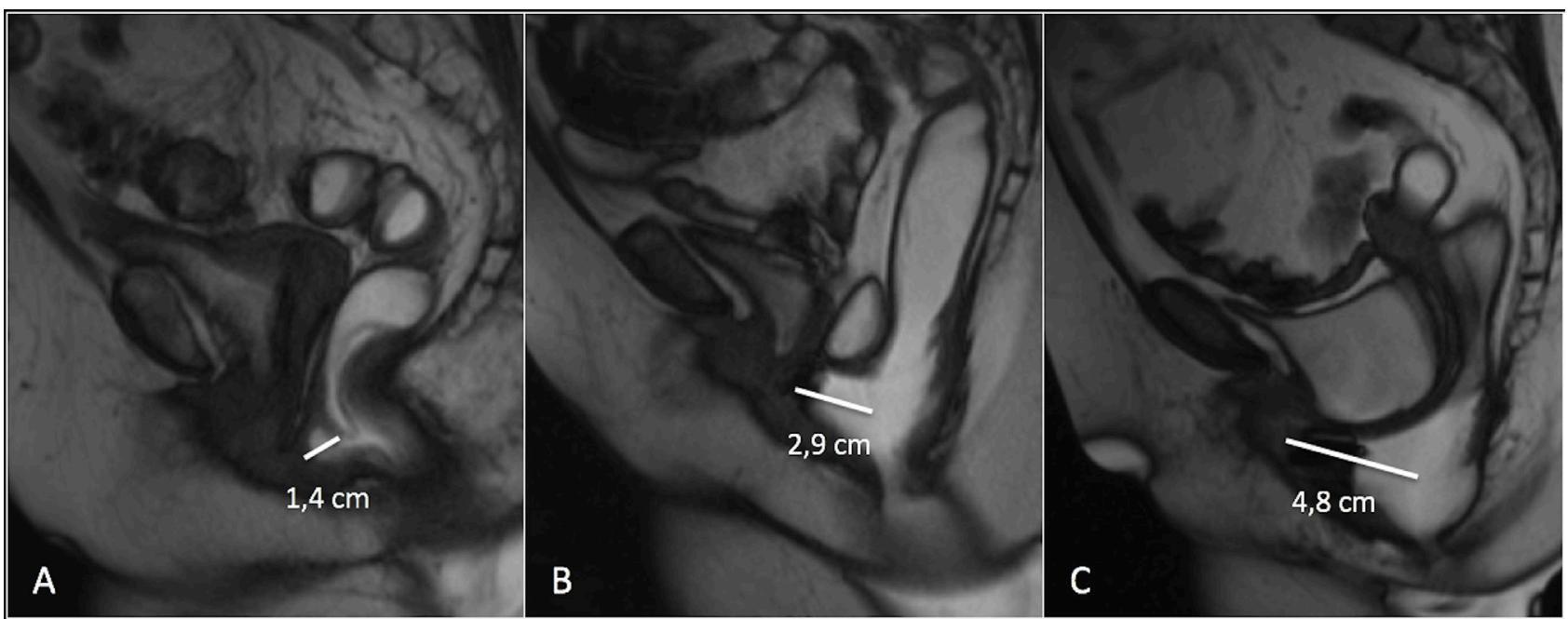

Figura 7 A, B y C: RM pelvis sagital en línea media en fase defecatoria que ilustran rectoceles de distinto grado de severidad. (A) Rectocele anterior pequeño, (B) Rectocele anterior moderado y (C) Rectocele anterior grande. 
Enterocele: Se producen cuando las asas intestinales y estructuras peritoneales protruyen hacia inferior por delante de la pared anterior del recto. Pueden ser simples o complejos dependiendo de la presencia de prolapso de cúpula vaginal, lo que es relevante para la planificación quirúrgica.

Cuando ocurre al final de la evacuación, puede producir una obstrucción defecatoria, que se manifiesta como pujo repetitivo e improductivo.

Las pacientes histerectomizadas son propensas al prolapso vaginal, por presentar un amplio un espacio recto-vaginal, que predispone al enterocele y peritoneocele ${ }^{15}$. Un gran cistocele puede enmascarar un enterocele o rectocele coexistente por un ajustado espacio en el piso pélvico. El enterocele puede clasificarse según el descenso bajo la LPC en: leve $<3 \mathrm{~cm}$; moderado 3-6 cm; severo $>6 \mathrm{~cm}$ (Figura 8).

El enterocele con peritoneocele se define como la herniación peritoneo hacia caudal por el septo recto-vaginal, anterior al recto. Característicamente ocurre por una debilidad de la fascia recto-vaginal, separándose el compartimiento medio del posterior y ocurriendo un descenso del peritoneo que puede contener asas de intestino delgado, colon sigmoides y/o tejido adiposo omental.

Invaginación rectal: Según su ubicación se divide en anterior, posterior o circunferencial. Puede comprometer el espesor completo de la pared rectal o sólo la mucosa. Según su extensión, se clasifica en recto-rectal, cuando se extiende sólo hasta el recto; recto-anal, cuando se extiende hasta el canal anal; y extra-anal o prolapso rectal cuando se extiende distal al margen anal externo ${ }^{16,17}$. Las invaginaciones recto-rectal y recto-anal pueden causar obstrucción mecánica al paso de las heces, mientras que los pacientes con prolapso rectal pueden presentar constipación, úlcera rectal con sangrado e incontinencia rectal (Figura 9).

Síndrome del piso pélvico espástico: También denominado disinergia defecatoria, contracción paradojal del músculo puborrectal y anismo ${ }^{5}$. Este síndrome se caracteriza por ser un trastorno funcional que afecta a pacientes que sufren de constipación y sensación de defecación incompleta, secundario a una evacuación frustra por contracción involuntaria, inapropiada y paradójica de la musculatura estriada del piso pélvico, en particular del músculo puborrectal $^{8}$. Se asocia además a ausencia de relajación del puborrectal con maniobras de defecación. En la D-RM, esta patología se manifiesta como hipertrofia del puborrectal, retardo entre la apertura del canal anal y la defecación, falta de descenso de la pelvis y contracción paradójica del puborrectal con reducida apertura del ángulo ano-rectal, determinando una evacuación prolongada o incompleta (Figura 10). Es frecuente la asociación al rectocele anterior ${ }^{18}$. Es fundamental un diagnóstico adecuado de esta patología, ya que se maneja clínicamente con bio-feedback.

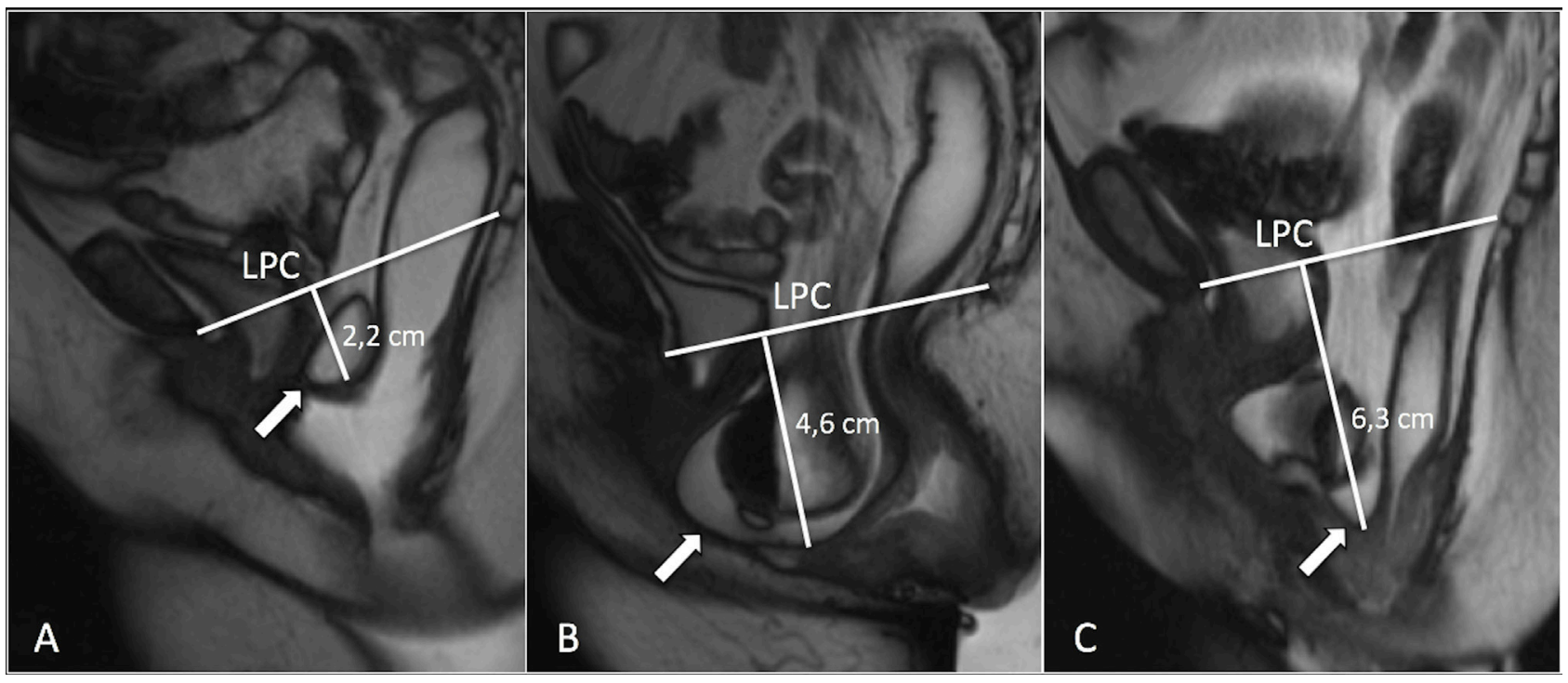

Figura 8 A, B y C: RM pelvis sagital en línea media en fase defecatoria que ilustran enteroceles de distinto grado. (A) Enterocele pequeño, $(B)$ enterocele moderado y $(C)$ enterocele grande. 


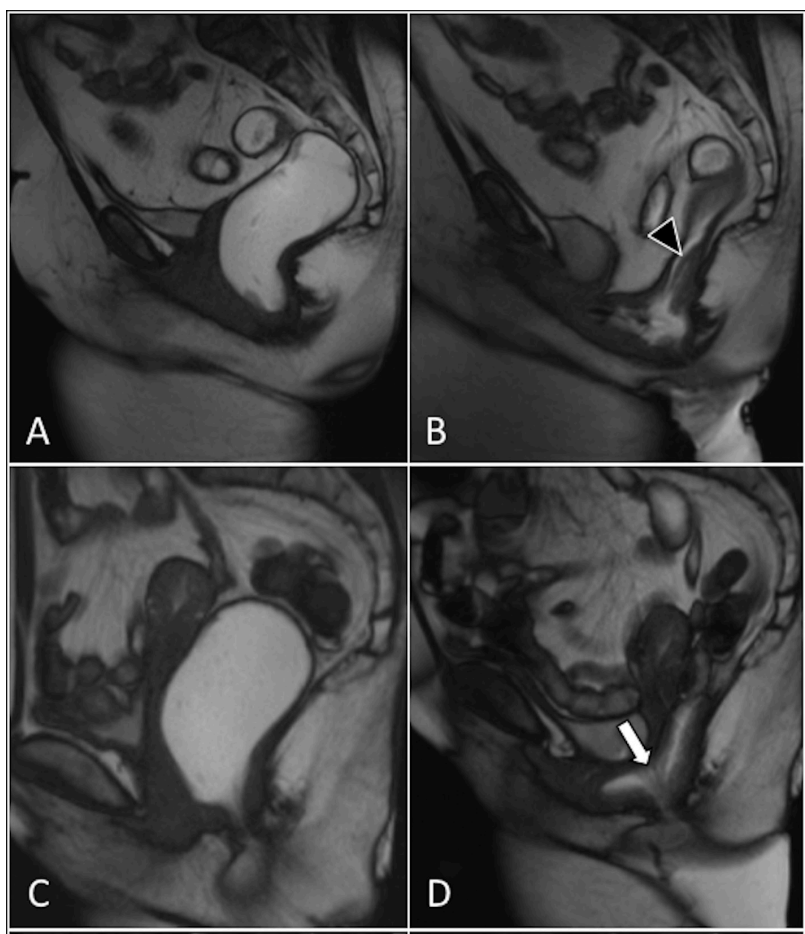

Figura $9 \boldsymbol{A}, \boldsymbol{B}, \boldsymbol{C}, \boldsymbol{D}, \boldsymbol{E}$ y $\boldsymbol{F}: \mathrm{RM}$ pelvis sagital en línea media. La imagen $(A)$ fase en reposo y $(B)$ en fase defecatoria, demuestran un engrosamiento de la pared rectal determinada por una invaginación intra-rectal obstructiva (punta de flecha negra). La imagen $(C)$ en reposo y $(D)$ en fase defecatoria, ilustran una invaginación intra-anal que causa obstrucción en la evaluación de un rectocele anterior y del recto. La imagen $(E)$ en reposo y $(F)$ en fase defecatoria muestra un prolapso de la pared rectal a través del canal anal.

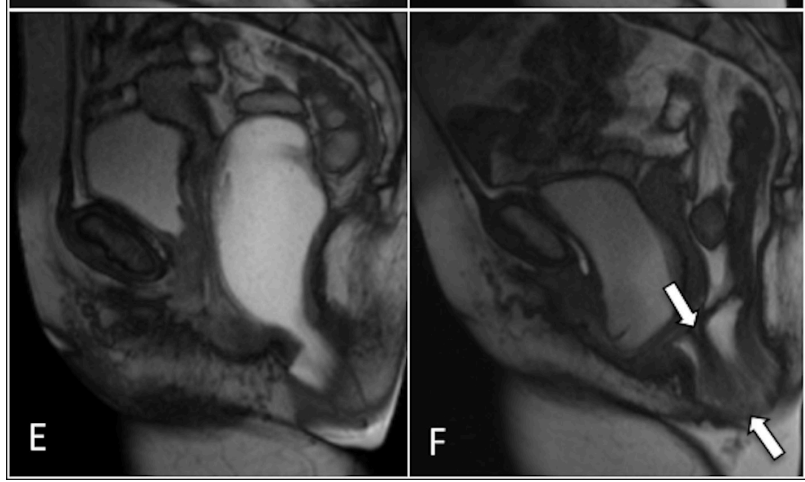

Síndrome de descenso perineal: Constituye una causa funcional de incontinencia anal, caracterizada por una marcada disminución del tono muscular del piso pélvico, secundaria a neuropatía del pudendo, con un descenso significativo de las estructuras (vejiga, útero y recto) durante las fases de valsalva y defecación $n^{16}$. Este síndrome se asocia a partos vaginales y a un aumento crónico de la presión intrarectal en pacientes con historia de pujo. El descenso excesivo del piso pélvico se define como $>2 \mathrm{~cm}$ de la LPC, con extensión de las líneas H y M (Figura 11).

Síndrome de la ulcera rectal solitaria: Trastorno benigno infrecuente, caracterizado por una isquemia de la mucosa secundaria al aumento de la presión extrínseca en la pared rectal en contexto de intu-

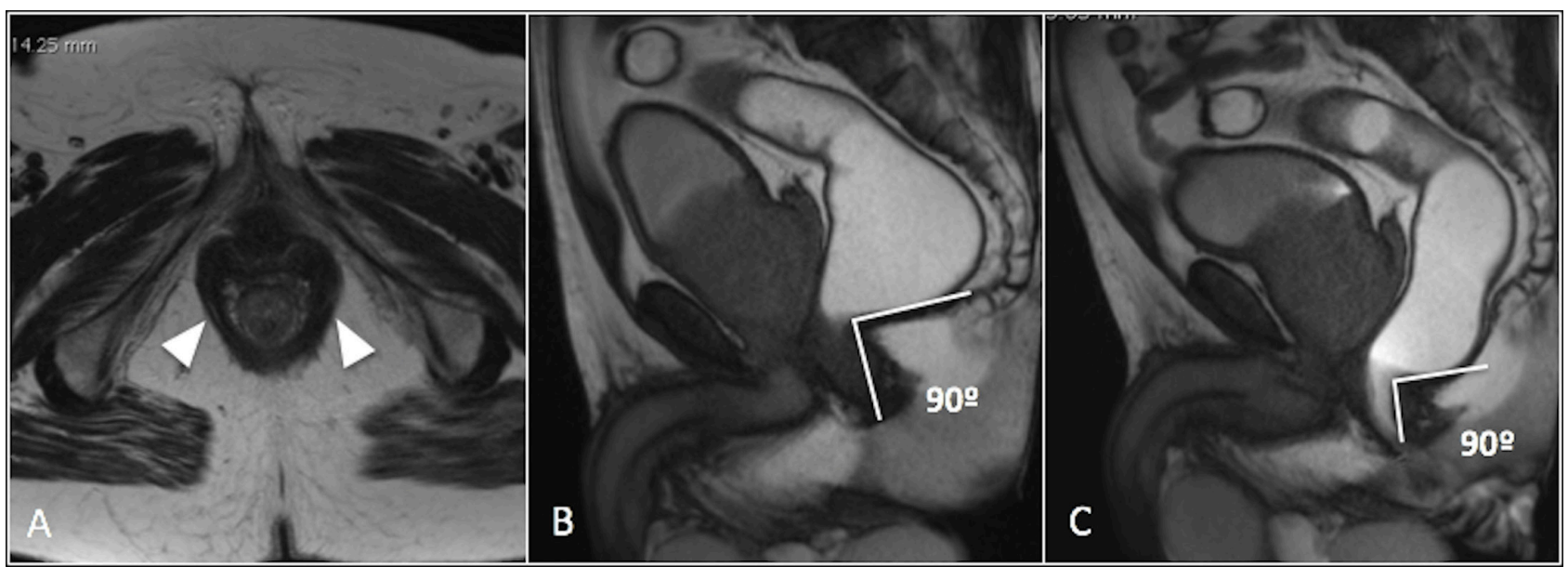

Figura 10 A, B y C: RM pelvis ponderada en T2 en plano axial (A), sagital en línea media en fase de reposo (B) y defecatoria (C). Se observa engrosamiento del fascículo puborrectal (flecha blanca en A) y contracción mantenida del puborrectal lo que mantiene un ángulo ano-rectal de $90^{\circ}$ durante la fase de contracción (B) y durante la fase defecatoria (C), compatible con síndrome del piso pélvico espástico. 


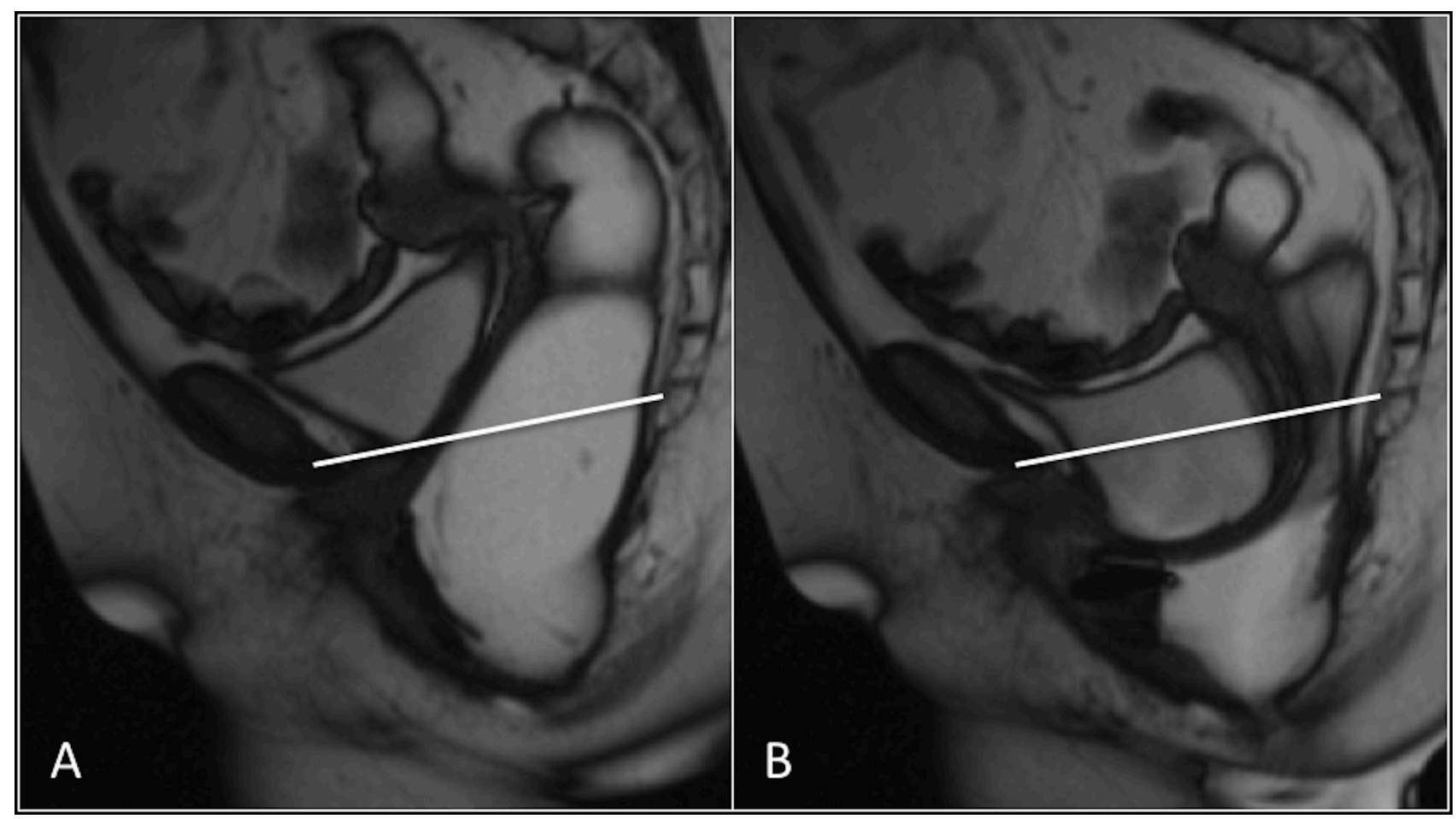

Figura 11 A y B: RM pelvis ponderada en T2 en planos sagitales en fase de reposo (A) y fase defecatoria (B). Se observa descenso del piso pélvico mayor de $2 \mathrm{~cm}$ de la $L P C$, con alargamiento excesivo de las líneas $H$ y $M$, compatible síndrome de descenso perineal.

suscepción o síndrome del piso pélvico espástico, manifestándose clínicamente como evacuación dolorosa incompleta. El diagnóstico se realiza por biopsia identificando un engrosamiento de la lámina propia y de la muscular de la mucosa. En imágenes se puede observar prolapso rectal, engrosamiento parietal, estenosis rectal y de forma variable úlcera rectal múltiple, única o más frecuentemente inexistente ${ }^{19}$.

\section{Conclusión}

La D-RM es una modalidad rápida y de alto rendimiento en la evaluación anatómica y funcional del piso pélvico, que evalúa los tres compartimientos que lo componen de forma simultánea y permite la visualización de tejidos blandos perirrectales de una forma menos invasiva que la defecografía convencional y sin utilizar radiación ionizante.

En la actualidad se recomienda como estudio de primera línea para la evaluación de las patologías que afectan el piso pélvico, lo que, en conjunto con la evaluación por un equipo multidisciplinario, permitirá tomar decisiones para un manejo óptimo.

\section{Referencias}

1. lacobellis F, Brillantino A, Renzi A, Monaco L, Serra $\mathrm{N}$, Feragalli $\mathrm{B}$, et al. MR Imaging in Diagnosis of Pelvic Floor Descent: Supine versus Sitting Position. Gastroenterol Res Pract. 2016; 2016: 9-11.

2. Del Salto LG, Criado J de M, del Hoyo LFA, Velasco LG, Rivas PF, Paradela MM, et al. Mr imaging-based assessment of the female pelvic floor. Radiographics. 2014; 34(5): 1417-1439.

3. Chamié LP, Ribeiro DMFR, Caiado AHM, Warmbrand G, Serafini PC. Translabial US and dynamic MR imaging of the pelvic floor: Normal anatomy and dysfunction. Radiographics. 2018; 38(1): 287-308.

4. Ahmad AN, Hainsworth A, Williams AB, Schizas AMP. A review of functional pelvic floor imaging modalities and their effectiveness. Clin Imaging. 2015; 39(4): 559565.

5. Maglinte DDT, Hale DS, Sandrasegaran K. Comparison between dynamic cystocolpoproctography and dynamic pelvic floor MRI: Pros and cons: Which is the "functional" examination for anorectal and pelvic floor dysfunction? Abdom Imaging. 2013; 38(5): 952-973.

6. Bertschinger KM, Hetzer FH, Roos JE, Treiber K, Marincek $B$, Hilfiker PR. Dynamic MR imaging of the pelvic 
floor performed with patient sitting in an open-magnet unit versus with patient supine in a closed-magnet unit. Radiology. 2002; 223(2): 501-508.

7. Poncelet E, Rock A, Quinton JF, Cosson M, Ramdane $\mathrm{N}$, Nicolas L, et al. Dynamic MR defecography of the posterior compartment: Comparison with conventional X-ray defecography. Diagn Interv Imaging. 2017; 98(4): 327-332.

8. Colaiacomo MC, Masselli G, Polettini E, Lanciotti S, Casciani E, Bertini L, et al. Dynamic MR imaging of the pelvic floor: A pictorial review. Radiographics. 2009; 29(3): 1-42.

9. Flusberg M, Sahni VA, Erturk SM, Mortele KJ. Dynamic MR defecography: Assessment of the usefulness of the defecation phase. Am J Roentgenol. 2011; 196(4): 394-399.

10. Boyadzhyan L, Raman SS, Raz S. Role of static and dynamic MR imaging in surgical pelvic floor dysfunction. Radiographics. 2008; 28(4): 949-967.

11. Fielding JR. Practical MR imaging of female pelvic floor weakness. Radiographics. 2002; 22(2): 295-304.

12. Hausammann R, Steffen T, Weishaupt D, Beutner U, Hetzer FH. Rectocele and intussusception: Is there any coherence in symptoms or additional pelvic floor disorders? Tech Coloproctol. 2009; 13(1): 17-26.

13. Macura KJ, Genadry RR. Female urinary incontinence: Pathophysiology, methods of evaluation and role of MR imaging. Abdom Imaging. 2008; 33(3): 371-380.

14. Law YM, Fielding JR. MRI of pelvic floor dysfunction: Review. Am J Roentgenol. 2008; 191(6): 45-53.

15. Tomšič MV, Podkrajšek M. Dynamic MR imaging of pelvic floor dysfunction. Appl Radiol. 2017; 46(8): 21-27.

16. O’Brien A. Patología del piso pelviano: Evaluación por imágenes. Rev Médica Clínica Las Condes. 2013; 24(2): 287-292.

17. Mortele KJ, Fairhurst J. Dynamic MR defecography of the posterior compartment: Indications, techniques and MRI features. Eur J Radiol. 2007; 61(3): 462-472.

18. Salvador JC, Coutinho MP, Venâncio JM, Viamonte B. Dynamic magnetic resonance imaging of the female pelvic floor-a pictorial review. Insights Imaging. 2019; 10(1): 15-16.

19. Zhu QC, Shen RR, Qin HL, Wang Y. Solitary rectal ulcer syndrome: Clinical features, pathophysiology, diagnosis and treatment strategies. World J Gastroenterol. 2014; 20(3): 738-744. 